\title{
1 Urban construction and demolition waste and landfill failure in
}

\section{Shenzhen, China}

3

4

5 Hong Yang ${ }^{a, b, c, *}$, Junqiang Xia ${ }^{a,{ }^{*}}$, Julian R. Thompson ${ }^{d}$, Roger J. Flower ${ }^{d}$

6

7 a State Key Laboratory of Water Resources and Hydropower Engineering Sciences, Wuhan University,

8 Wuhan 430072, China

$9{ }^{b}$ Norwegian Institute of Bioeconomy Research (NIBIO), Postboks 115, 1431, Ås, Norway

$10{ }^{\mathrm{c}}$ CEES, Department of Biosciences, University of Oslo, Blindern, 0316, Oslo, Norway

11 d UCL Department of Geography, University College London, London, WC1E 6BT, UK

12

13 Correspondence authors:

14 hongyanghy@gmail.com (H. Yang); xiajq@whu.edu.cn (J. Xia) 
Abstract

17

On December 20, 2015 at 11:40 am a landslide in one of China's most advanced cities, Shenzhen, killed 73 people and damaged 33 buildings. In the absence of heavy rainfall or earthquakes, the landslide was an unexpected and profound shock to many people. According to China's Ministry of Land and Resources, the landslide was triggered by the collapse of an enormous pile of construction and demolition waste (CDW). With China's rapid urbanization, an increasing amount of CDW is being generated, especially in major cities. In total, China produces some $30 \%$ of the world's municipal solid waste and of this about $40 \%$ is CDW. To prevent landslides associated with CDW, the volume of waste dumped in landfills should be regulated to minimize risk. More specifically 4-Rs (reduce, reuse, recycle and recover) policies should be implemented more widely and efficiently. Although landfill will continue to be an important disposal option, proper management and careful monitoring of CDW are urgently needed to satisfy pressing safety issues. International collaboration, sharing of knowledge, and use of the latest technologies are needed so that the similar landslides can be prevented in China and elsewhere.

Keywords Landslide, Construction and Demolition Waste, 4-Rs (Reduce, Reuse, Recycle and Recover) 


\section{Introduction}

A landslide that occurred in Shenzhen, Southern China on December 20, 2015 killed 73 people and damaged 33 buildings (China Government, 2016). China experiences many landslides and most are triggered either by the heavy and prolonged rainfall that characterizes the East Asian monsoon, or by earthquakes, such as the Wenchuan earthquake of 2008 (Xu et al., 2013). In the case of Shenzhen, however, there was less than $5 \mathrm{~mm}$ of rain in the ten days before the landslide and no earthquake activity was reported in the area. According to China's Ministry of Land and Resources (MLR), this landslide was triggered by the collapse of an enormous pile of construction debris (MLR, 2015). With China's unprecedented rate of urbanization, more construction and demolition waste (CDW) is being generated, particularly within the county's megacity zones such as Beijing, Shanghai, Guangzhou and Shenzhen. Without significant reduction and proper management of CDW and other household/industrial waste, disasters such as the one that befell Shenzhen will be repeated. Here we argue that the 4-Rs (reduce, reuse, recycle and recover) for CDW, proper disposal of waste, and strict management and monitoring of landfill sites are all required to reduce the risks of similar landslides occurring in the future.

\section{A landslide triggered by collapse of construction debris}

The site of the 2015 landfill failure in Shenzhen was in the Guangming New District (Fig. 1b). The design lifetime of this temporary landfill expired in February 2015. Despite warnings from an environmental consulting firm in early 2015, CDW continued to be dumped at the site. At around 11:40 am on Dec 20, 2015 the construction debris collapsed and travelled a distance of around $750 \mathrm{~m}$ (Fig. 2). In a matter of minutes, the landside swamped 33 buildings that included factories, worker dormitories and apartments

(Fig. 1d, Fig.2, Fig.3). The landslide impact area was around $0.38 \mathrm{~km}^{2}$, with a length of $1100 \mathrm{~m}$ from south to north and a width ranging from 150 to $630 \mathrm{~m}$ (Liu, 2016). The total volume of the landslide was 
estimated to be $2.7 \times 10^{6} \mathrm{~m}^{3}$. The depth of the landslide debris ranged from 3 to $16 \mathrm{~m}$, with an average of 6-7 m.

After the landslide, more than 5,000 rescue workers and 700 excavators have worked on digging and removing debris and searching for survivors. Over 300 medical workers and 50 mental health professionals were actively involved in the disaster relief and recovery work (Yang et al., 2016b). After 27 days of rescue excavation, $0.94 \times 10^{6} \mathrm{~m}^{3}$ of material had been removed, 1 person was pulled out alive and 42 corpses had been exhumed from the soil (Li et al., 2016). In total, at least 73 people were killed, 17 were injured and 4 are still missing. The total economic loss is estimated to be more than 0.881 billion RMB (equivalent to 0.13 billion USD).

Shenzhen was just a quiet fishing village in Guangdong Province when China initiated economic reform and opening up policies in the late 1970s. Over the last four decades, thanks to its status as a special economic zone, tax reductions, cheap land resources and proximity to Hong Kong (Fig. 1a), Shenzhen leapfrogged ahead of most Chinese cities and has become a major industrial centre surrounded by sprawling industrial parks. Along with unparalleled industrialization and urbanization, infrastructure development included construction of Asia's largest underground train station (Futian) and metro transportation network. Property development consequently soared but some new buildings were initially poorly constructed, the so called Doufuzha (toufu-dreg) developments. In addition many old buildings, particularly Chengzhongcun (villages in the city) persisted as the city grew. In the 1990s, demolition and rebuilding of these and other buildings increased sharply and Shenzhen's capacity to store CDW was exceeded by 2015. Similar severe CDW storage problems have occurred in other Chinese cities, including Beijing, host of the 2008 Summer Olympics and the forthcoming 2022 Winter Olympics, and Nanjing, host of the Youth Olympics in 2014. In total, China produces some $30 \%$ of the world's municipal solid waste and of this about $40 \%$ is CDW (Huang and Xu, 2011). In absolute terms, the construction of new buildings and demolition of old properties annually generates around 100 and 200 million tons of waste, respectively. 
The Shenzhen landslide in one of China's most advanced cities and in the absence of heavy rainfall or earthquake activity was a profound shock to many Chinese people. Why did it happen? MLR's preliminary report stated that within the landfill site "the [CDW] accumulation was large and too steep, causing a loss of stability" (MLR, 2015). The height of the landfill was approximately $155 \mathrm{~m}$ (Liu, 2016) and the average slope angle was around $35^{\circ}$ (Zou, 2016). Clearly, more studies are needed to further improve the accuracy of slope angle. Experiments can be conducted to measure the frication angle of CDW. The comparison between friction angle and slope angle can provide more information about the reason of the landslide in Shenzhen. The original design capacity of the landfill was $4 \times 10^{6} \mathrm{~m}^{3}$. However before the landslide the estimated volume of the landfill was $5.8 \times 10^{6} \mathrm{~m}^{3}, 45 \%$ above its design capacity. Clearly, the shear strength of the solid waste was critically exceeded but this key geotechnical threshold is a function of many factors including waste type composition, compaction, organic matter content, degree of decomposition, moisture conditions, accumulation duration, and overburden pressure (Arulrajah et al., 2014). Water was a likely significant factor, either by causing internal erosion as a result of water ingress to the site and through-flow creating pore water pressure and destabilizing poorly compacted soil layers.

The original location of the landfill was an abandoned quarry pit that was surrounded by hilly ridges to the east, west and south. The pit itself faced north with the hillside sloping down from the quarry. Bedrock was relatively impervious weathered granite (Fig. 2) and when mining ceased in 2008 water began to slowly accumulate within the pit (water in the bottom of quarry, Fig. $1 \mathrm{c}$ ). This proceeded as the site was turned over to receive CDW landfill, mainly soil, which began to be dumped in March 2014. Poor drainage meant that groundwater levels rose, the dumped soil absorbed water (Fig. 2). Although a pipe and superficial impermeable drainage layers were installed in two of the ten terraces, they were far from sufficient to drain runoff from the surrounding hillsides. Surface water infiltration induced a gradual increase in pore water pressure that was also increasing due to the continual loading of waste. Eventually these processes triggered the landslide. 
(a)

(b)

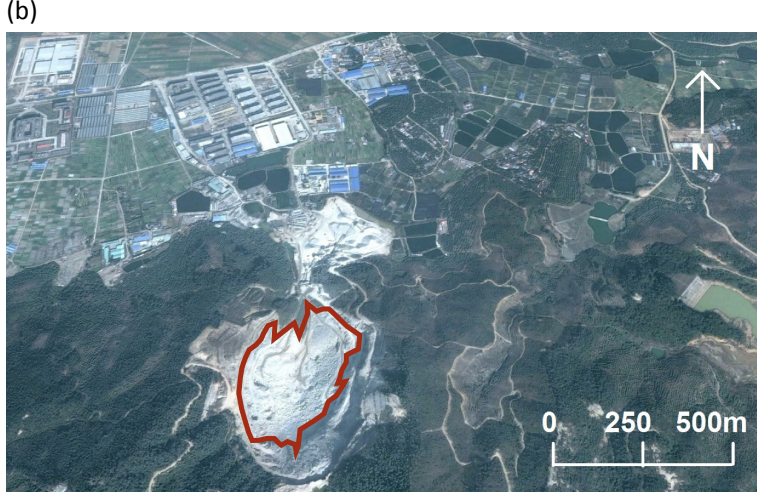

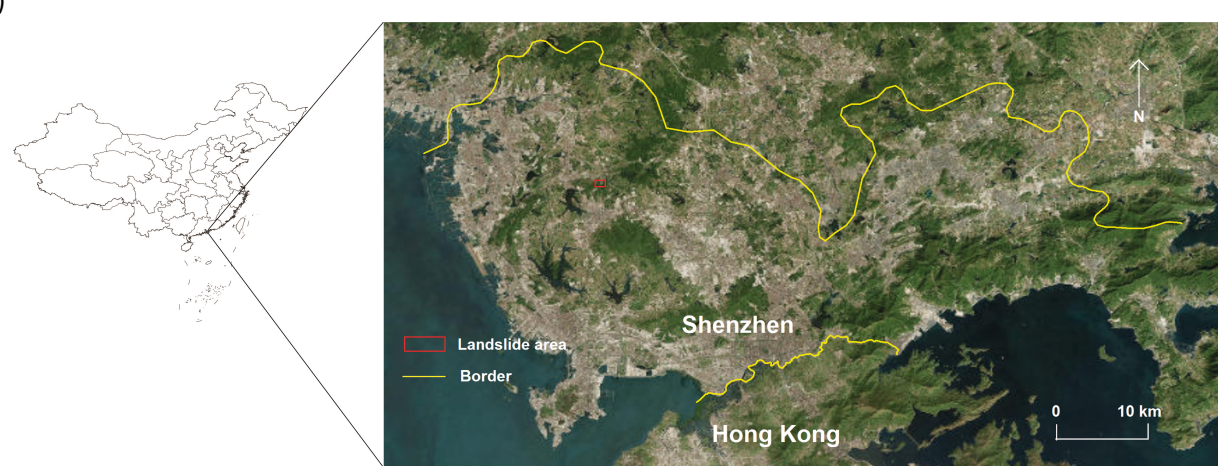

(c)

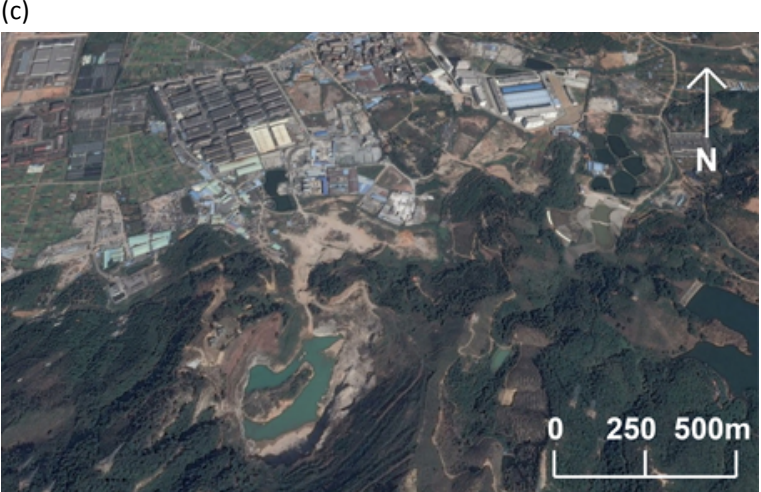

(d)

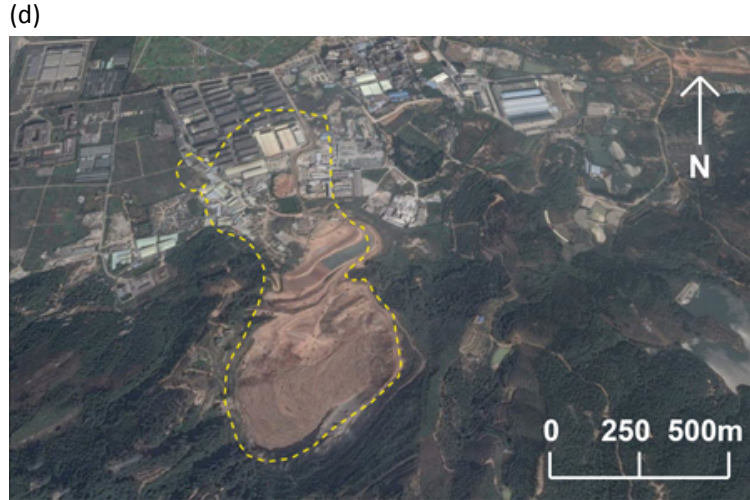

Fig. 1. The location and history of the Guangming New District landfill in Shenzhen, China.

(a) Location of Shenzhen and landslide site; (b) the Guangming New District landfill was a quarry and quarry is marked in red colour, image January 30, 2007,; (c) the abandoned quarry with residual water in the bottom, image November 25, 2013; (d) the quarry was used as a landfill to store construction and demolition waste, image November 23, 2014. The yellow broken line in (d) is the landslide boundary taken from the China National Administration of Surveying, Mapping and Geoinformation (NASMG). All high-resolution satellite images are from Google Earth. 

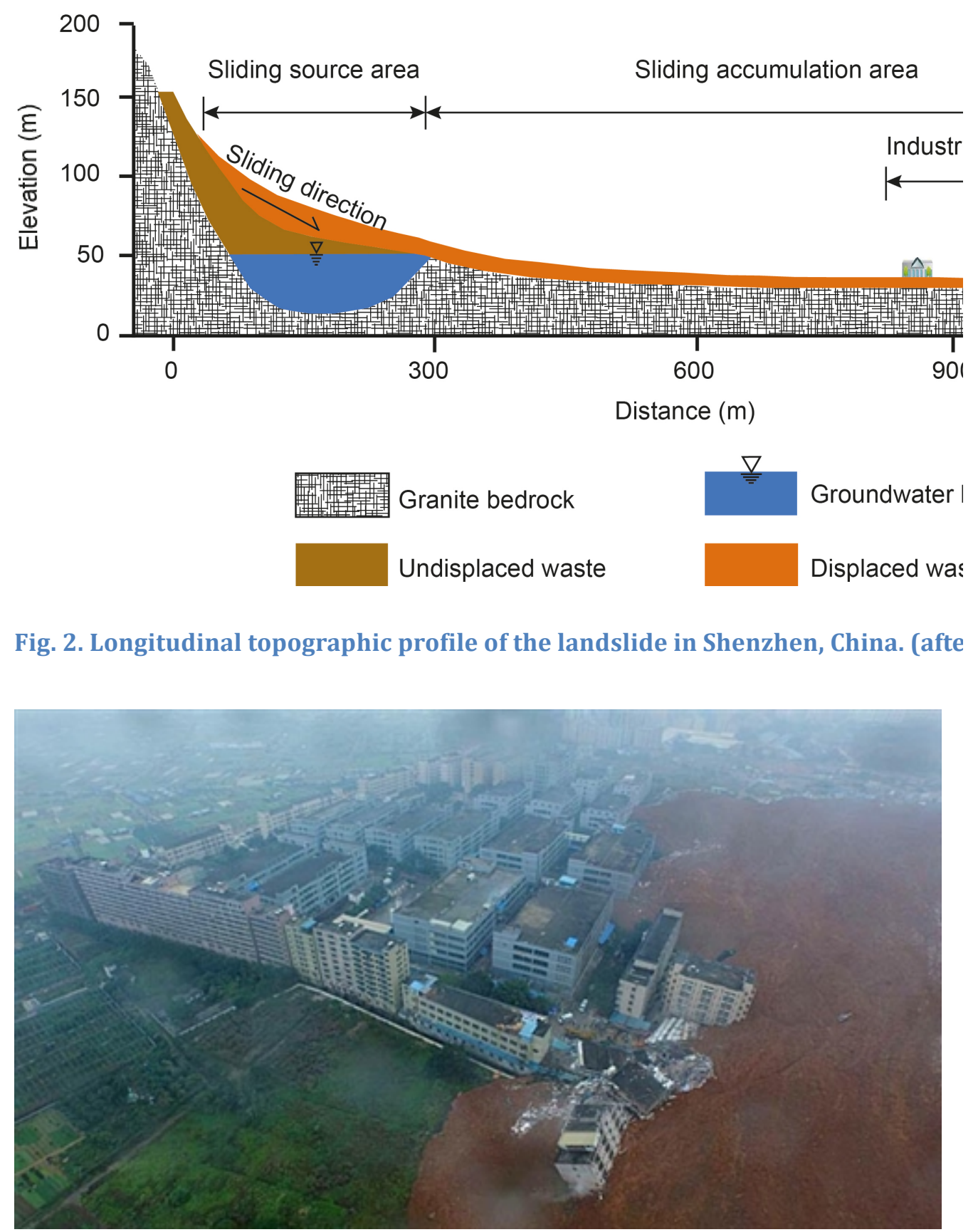

117 Fig. 3. Destroyed buildings engulfed by the Shenzhen landslide, 118 Image is from www.baidu.com 


\section{Mitigating the risk of CDW landfill failure}

The fundamental issue in preventing landslides associated with CDW is to reduce the volume of waste dumped in landfills and to impose safe operating practices. In particular, 4-Rs (reduce, reuse, recycle and recover) policies should be implemented (Hoornweg and Bhada-Tata, 2012; Yang et al., 2016a) (Fig. 4a). Construction waste minimization at the design stage is the most efficient approach, yet this is not generally acknowledged by over $60 \%$ of Chinese architects (Hao and Kang, 2010). Hazardous or toxic material should be the primary target for waste reduction. Any excessive excavation of foundations should also be avoided, particularly if the site is contaminated. New materials technology, such as prefabrication and 3D printing instead of in situ small-scale fabrication could also be used more widely to reduce waste. Low- density waste should be fully compacted before the dumping.

Re-using can simply mean moving material from one application to another. Recycling and recovery processes can be used to transform CDW material into new products. Excavated soil is a valuable material if correctly used to fill uneven ground. With appropriate health and safety standards and professional advice, subsoils can also be upgraded to topsoils by mixing with composted municipal garden and green waste (Ferguson et al., 1995). Wood, steel, concrete and other materials can also be reused or recycled. In China, approximately $20 \%$ of waste is collected and recycled by informal waste picking (Hoornweg and Bhada-Tata, 2012) but rigorous health and safety procedures are required to safeguard human health. Developing a mature market for trading recycled CDW is an important economic approach that could promote reuse and recycling. As the Chinese city with the most mature market economy, Shenzhen could initiate this kind of market with the potential for it to be replicated throughout the country.

Despite reducing waste volumes, excess disposal may still continue when landfill capacities cannot meet increasing waste production. The 4-Rs can be used to reduce the waste volume, while the proper disposal of waste is equally indispensable. Landfill will continue to be an important disposal option, but proper management supported by disposal regulations enforced by law and with effective enforcement is needed to ensure safety. Before landfill operations commence, a thorough geotechnical investigation is needed to determine the bedrock, soil, water, vegetation and other condition on the site that might, 
if not mitigated, lead to the same problems responsible for the Shenzhen landslide. The nature of the infill materials, their characteristics and the configuration of the site are particular concerns. Of special importance is the water content of the landfill material and its management (Lavigne et al., 2014) (Fig. 4b). Homogeneous permeability and efficient drainage systems need to be established to keep water contents within safe limits. Stabilization measures, such as the establishment of suitable vegetation cover on topsoil, should be taken to prevent soil erosion and seepage of surface runoff. In addition, detailed monitoring potentially combining terrestrial surveying, aerial imagery and satellite remote sensing techniques should be undertaken to regularly assess landfill stability (Fig. 4c). The height and slope angles of waste piles should be carefully measured and monitored to avoid safe limits being exceeded. In sites with the potential for groundwater pollution and high methane emissions, additional monitoring is needed to reduce risks of pollution, explosion or fire. For example, GPS, terrestrial LiDAR (Light Detection and Ranging) and EROS-B (Earth Remote Observation System-B) have been integrated to monitor land movement and morphological changes in landfills in Campania, Italy (Addabbo et al., 2015). Through careful monitoring, significant changes in landfill stability can be used to provide early warnings to people living in landslide-prone areas. 
(a)

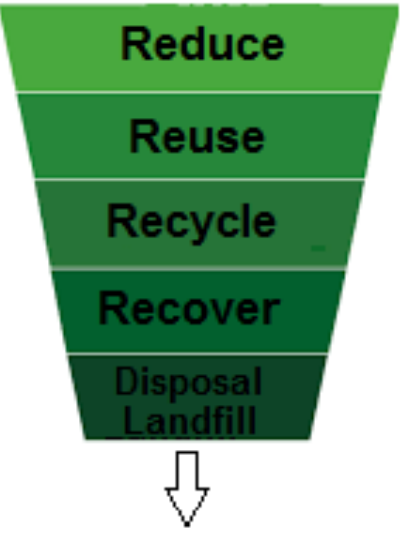

(b)

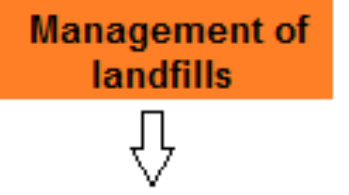

(c)

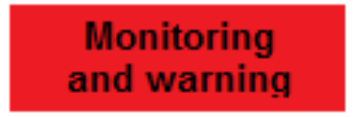

Fig. 4. Measures to mitigate the construction and demolition waste and landfill failure. (a) Reduce, reuse, recycle and recover before disposal of construction and demolition waste; (b) Systematic management of landfills; (c) Careful monitoring landfills and early warning of any dangers

There are regulatory policies in China for handling waste, for example Regulations on Urban

Waste, but there is lack of explicit national legislation governing CDW management. Some cities and provinces are developing local responses to CDW management. For example, in recent years several mega cities including Shenzhen and Beijing have established directives to manage CDW by tightening regulations and imposing penalties on improper dumping. However, enforcement of these regulations and directives is very important (Yang et al., 2015). On January 9, 2016, charges were brought against 16 Shenzhen officials for abuse of authority and dereliction of duty that may have contributed to the landslide.

\section{International collaboration}

In China and other countries experiencing similar rapid and extensive urbanization, CDW management is emerging as an international challenge. Developed countries have practiced the 4-Rs for decades and have 
accumulated valuable experience. For example, Austria achieved 70\% recycling of all waste in 2010 thanks to the EU Waste Framework Directive (Defra, 2014). The Construction \& Demotion Recycling Association (CDRA) was set up in 2013 whilst the International Geotechnical Society UNESCO Working Party on World Landslide Inventory (WPWLI) has accumulated a wealth of relevant expertise. The Shenzhen disaster highlights again the urgency of managing rapid urbanization and industrialization in rapidly developing countries (Zhou and Zhao, 2013). International collaboration and sharing of the latest knowledge and technology need to be facilitated globally so that the similar landslides are prevented in the future (Guerrero et al., 2013).

The Shenzhen disaster should be a wake-up call for regulators rather than be the harbinger of more CDW storage disasters in rapidly developing regions of China and elsewhere.

\section{Acknowledgements}

The authors would like to thank financial supports from the Open Research Fund Program of State Key Laboratory of Water Resources and Hydropower Engineering Science, Wuhan University (No. 2015HLG02), and the Scientific Special Expenditure for Non-profit Public Industry from the MWRC (Grant No. 201401038).

\section{References}

Addabbo, P., Di Bisceglie, M., Focareta, M., Maffei, C., Ullo, S., 2015. Integration of satellite observations and ground-based measurements for landfill monitoring, Metrology for Aerospace (MetroAeroSpace), 2015 IEEE. IEEE, Benevento, pp. 411-415.

Arulrajah, A., Disfani, M.M., Horpibulsuk, S., Suksiripattanapong, C., Prongmanee, N., 2014. Physical properties and shear strength responses of recycled construction and demolition materials in unbound pavement base/subbase applications. Constr. Build. Mater. 58, 245-257.

China Government, 2016. 69 people found dead in Shenzhen landslide Accessed online <http://www.gov.cn/xinwen/2016-01/13/content_5032448.htm>. 
Defra, 2014. Energy from waste: A guide to the debate Accessed online

<https://www.gov.uk/government/publications/energy-from-waste-a-guide-to-the-debate>.

Ferguson, J., Kermode, N., Nash, C.L., Sketch, W.A.J., Huxford, R.P., 1995. Managing and minimizing construction waste: a practical guide. Institution of Civil Engineers, London.

Guerrero, L.A., Maas, G., Hogland, W., 2013. Solid waste management challenges for cities in developing countries. Waste Manage. 33, 220-232.

Hao, Y., Kang, J., 2010. Current situation and potentials of construction waste minimisation by design in china through a comparative survey between China and UK. Building Sci. 26, 4-9.

Hoornweg, D., Bhada-Tata, P., 2012. What a waste: a global review of solid waste management. World Bank, Washington, DC, USA.

Huang, X., Xu, B., 2011. On the legal regulation of the reduction and utilization of the construction waste based on eco-efficiency. Urban Stud. 18, 90-94.

Lavigne, F., Wassmer, P., Gomez, C., Davies, T.A., Hadmoko, D.S., Iskandarsyah, T.Y.W., Gaillard, J., Fort, M., Texier, P., Heng, M.B., 2014. The 21 February 2005, catastrophic waste avalanche at Leuwigajah dumpsite, Bandung, Indonesia. Geoenviron. Disasters 1, 1-12.

Li, H., Qin, J., You, S., 2016. Technological management of emergency rescue of "12.20" major landslide in Shenzhen. Yangtze River 47, 1-9.

Liu, C., 2016. Genetic mechanism of landslide tragedy happened in Hong'ao dumping place in Shenzhen, China. The Chinese Journal of Geological Hazard and Control 27, 1-5.

MLR, 2015. Shenzhen landslide is a production safety accident Accessed online <http://www.mlr.gov.cn/xwdt/jrxw/201512/t20151226_1393024.htm>.

Xu, C., Xu, X.W., Dai, F.C., Wu, Z.D., He, H.L., Shi, F., Wu, X.Y., Xu, S.N., 2013. Application of an incomplete landslide inventory, logistic regression model and its validation for landslide susceptibility mapping related to the May 12, 2008 Wenchuan earthquake of China. Nat. Hazards 68, 883-900.

Yang, H., Huang, X., Thompson, J.R., Bright, R.M., Astrup, R., 2016a. The crushing weight of urban waste. Science 351, 674-674.

Yang, H., Huang, X., Thompson, J.R., Flower, R.J., 2015. Enforcement key to China's environment. Science 347, 834-835. 
237 Yang, H., Huang, X.J., Thompson, J.R., Flower, R.J., 2016b. Chinese landfill collapse: urban waste and human 238 health. Lancet Glob. Health 4, e452.

239 Zhou, N.Q., Zhao, S., 2013. Urbanization process and induced environmental geological hazards in China. Nat.

240 Hazards 67, 797-810.

241 Zou, D., H., 2016. Exploring a waste dump site failure - Possible causes and prevention measures. Int. J.

242 Geohazards Environ. 2, 25-33.

243 